\title{
Evaluation of Matrix Metalloproteinases-2 (MMP-2) and Tissue Inhibitors of Metalloproteinases-2 (TIMP-2) in Oral Submucous Fibrosis and Their Correlation With Disease Severity

\author{
Shrestha A, Carnelio S
}

Department of Oral Pathology and Microbiology

Manipal College of Dental Sciences Manipal University, Manipal, India

\section{Corresponding Author}

Sunitha Carnelio

Department of Oral Pathology and Microbiology

Manipal College of Dental Sciences Manipal University, Manipal, India

Email: sunithacarnelio@yahoo.co.uk

Citation

Shrestha A, Carnelio S. Evaluation of Matrix Metalloproteinases-2 (MMP-2) and Tissue Inhibitors of Metalloproteinases-2 (TIMP-2) in Oral Submucous Fibrosis and Their Correlation with Disease Severity. Kathmandu Univ Med J 2013;44(4):274-281.

\section{ABSTRACT}

\section{Background}

Oral submucous fibrosis (OSF), a potentially malignant oral lesion, is a form of pathological fibrosis affecting the oral mucosa. It results from an imbalance in equilibrium of the normal process of synthesis and degradation of extra cellular matrix. Matrix metalloproteinases and its inhibitors play important role in remodeling of the extra cellular matrix which are important in progression and pathogenesis of potentially malignant lesions to malignancy.

\section{Objectives}

To evaluate the expression and distribution of Matrix metalloproteinases-2 (MMP2) and Tissue inhibitor of metalloproteinases-2 (TIMP-2) in different grades of Oral Submucous Fibrosis(OSF).

\section{Method}

Immunohistochemical analysis for MMP-2 and its TIMP-2 was performed in 30 histopathologically confirmed, formalin fixed, paraffin embedded specimens of OSF. A semi-quantitative analysis was done to assess the expression, distribution and comparison of these in various stages of this disease.

\section{Result}

All moderately advanced cases and $64.2 \%$ for MMP-2 and $78.5 \%$ for TIMP-2 of early stage cases showed positivity. Between two stages of OSF, statistically significant differences were noted in expression of TIMP-2 in lamina propria, deep connective tissue and supra basal layers $(p<0.05)$ and basal and supra basal layers for MMP-2 $(p<0.05)$.

\section{Conclusion}

The simultaneous increase in expression of MMP-2 and TIMP-2 with advancing stages of OSF can provide a basis for considering the proteases as important mediators in the pathogenesis and progression of OSF which could aid in identifying the aggressiveness of the condition and elucidate its role in its malignant transformation.

\section{KEY WORDS}

Immunohistochemistry, matrix metalloproteinases, oral submucous fibrosis, tissue inhibitors of metalloproteinases 


\section{INTRODUCTION}

Oral submucous fibrosis (OSF) is a chronic debilitating disease characterized by inflammation and progressive generalized sub mucosal fibrosis, leading to trismus. The World Health Organization Collaborating Centre for Oral Cancer and Pre Cancer has considered this condition to be a 'potentially malignant disorder' to reflect its widespread anatomical distribution. ${ }^{1}$ It exhibits characteristic histopathological features consisting of juxtaepithelial hyalinization and excessive collagen deposition in the connective tissue secondary to which, the epithelium becomes atrophic. ${ }^{1,2}$ Although the pathogenesis of OSF is not well established the increase in areca nut consumption is considered to be the prime causative agent which has been classified as a 'group one carcinogen' in the second IARC monograph. ${ }^{2,3}$

It has been observed that dynamics related to this process are associated with multiple factors, which includes areca nut and its products, prostaglandins, fibrogenic cytokines, etc and could bring about the proliferation of fibroblast and its products. Further, alteration in the extra cellular matrix (ECM) brought about by numerous proteolytic enzymes and its inhibitors could also play an important role. Among the various proteolytic enzymes released by stromal cells, Matrix Metalloproteinases (MMPs) play an important role in modulation of ECM.

MMPs are a family of zinc and calcium dependent proteolytic enzymes which are involved in a wide variety of biological processes ranging from physiological such as cell proliferation and differentiation to pathological states associated with inflammation, degeneration, tumor metastasis and growth. In normal tissue MMPs are expressed at very low levels and their production and activation is rapidly induced when active tissue remodeling is needed. Further, their activity is regulated by a group of specific tissue inhibitors of metalloproteinases (TIMP), a multi gene family of which TIMP-1 and TIMP-2 are well characterized. ${ }^{4,5}$

MMPs and TIMPs play a pivotal role in maintaining the balance in remodeling of the ECM and disruption of this balance may result in diseases associated with uncontrolled turnover of matrix. Since in OSF there is a disturbance in the homeostatic equilibrium between the synthesis and degradation of ECM, this study aims to investigate the role played by MMP- 2 and TIMP- 2 in normal oral mucosa and in the advancing stages of OSF.

\section{METHODS}

This laboratory based, retrospective study involved the use of 30 buffered, formalin fixed, paraffin embedded tissue blocks of histolopathologically proven cases of OSF, obtained from the archives of Department of Oral Pathology and Microbiology, Manipal College of Dental Sciences, Manipal. Ten tissue blocks of normal oral mucosa obtained from gingival and vestibular mucosa at the time of extraction of impacted teeth were used as normal controls. Cases were confirmed by two oral pathologists using haematoxylin and eosin stained sections among which 14 cases were of Early stage and 16 of Moderately advanced stage of OSF classified according to Pindborg and Sirasat. ${ }^{6}$ Cases associated with systemic sclerosis and history of trauma, surgery or radiotherapy for any head and neck lesions were excluded from the study. Five cases each of inflammatory bowel and placenta served as positive control for MMP-2 and TIMP-2, respectively. These cases were obtained from department of Pathology, Kasturba Medical College, Manipal and the endothelial staining of blood vessels was used as the internal positive control. The study was approved by University Ethics Committee (UEC/14/2010), Manipal University.

\section{Immunohistochemistry}

The immunohistochemical (IHC) analysis for MMP-2 and TIMP-2 was performed using streptavidin-biotinperoxidase technique. Paraffin-embedded OSF tissues were cut into 4- $\mu \mathrm{m}$ thick sections and taken onto two percent 3-amino propyl triethoxy silane solution (APES) (Sigma Aldrich Chemical Co., St Louis, MO, USA) adhesive coated micro slides and incubated overnight at $48^{\circ} \mathrm{C}$ in a slide warmer to ensure complete adhesion of sections. Antigen retrieval was carried out using commercial microwave antigen retrieval system where the sections were placed in a container with pre heated 10mM Tris EDTA buffer ( $\mathrm{pH} 9.0)$ at $96^{\circ} \mathrm{C}$ for three cycles of six minutes each. The sections were thoroughly wiped with tissue paper and subsequently rinsed with Tris Buffered Saline (TBS) at pH 7.6 for three minutes, which was repeated after every step. After rinsing in TBS, endogenous peroxidase activity was neutralized by incubating the slides with three percent hydrogen peroxide $\left(\mathrm{H}_{2} \mathrm{O}_{2}\right)$ in methanol for 20 minutes. This was followed by a power block for 20 minutes to block any non specific antigenic sites. The sections were subsequently incubated at room temperature for three hours with primary antisera mouse monoclonal primary antiMMP-2 diluted at 1:20 (NCL-MMP2-507, Clone: 17B11, Leica Biosystems New Castle Ltd, New Castle, UK) and antiTIMP-2 antibodies diluted at 1:20 (NCL-TIMP2-487, Clone: 46E5, Leica Biosystems New Castle Ltd, UK), in moist chamber. Post Primary Block was used to enhance penetration of the subsequent polymer reagent, incubated for 30 minutes in moist chamber. Subsequently, the slides were further incubated with secondary antibody horse radish peroxide (HRP) (NovoLinkTM Polymer) for 30 minutes. Visualization was performed using freshly prepared 3,3 diaminobenzidine tetrachloride (DAB) chromogen for 10 minutes. Finally slides were counterstained with Mayer's haematoxylin for 5 minutes followed by gentle wash under running tap water for a minute and air dried. Further, slides were dehydrated, dipped in xylene and mounted with dibutyl pthalate xylene (DPX) and cover slipped.

At every batch of staining protocol positive and negative 
controls were taken to determine the false positive and false negative expression in which slides used as negative control were subjected to same staining protocol except the primary antibody was replaced with TBS.

\section{Evaluation of Immunostaining}

Five areas of each section demonstrating MMP-2 and TIMP-2 positivity were randomly selected and analyzed. The evaluation was made for the number and distribution pattern of areas showing positivity for MMP-2 and TIMP-2 in the epithelium as well in the connective tissue in different stages of OSF as well as in normal oral mucosa. The positive cells were counted in two zones of epithelium namely basal and supra basal. Within the connective tissue the zones were divided as lamina propria and deep connective tissue. Staining was assessed independently by two observers to eliminate inter-observer bias. The numbers of cells showing positive staining were calculated per five high power field (HPF) at 400x magnification using light microscope.

\section{Statistical Analysis}

Data were analyzed statistically using Statistical Package for Social Sciences 11.5 (SPSS 11.5). Interclass correlation coefficient was calculated to find out the agreement between two observers, to remove the possible bias. Kruskal Wallis Test was applied to evaluate the significance between normal buccal mucosa and different stages of OSF. Wilcoxon Signed Ranks Test was done to compare the significant difference between the different zones of epithelium and connective tissue. Mann-Whitney $U$ Test was done to compare the significant difference between the different stages. A p-value less than 0.05 were considered to be statistically significant.

\section{RESULTS}

Clinical and Pathological features of the Specimens of
Early Stage and Moderately Advanced Stage of OSF

The study group comprised of $70 \%$ males and $30 \%$ females, with a mean age of 47.5 years of males and 42.4 years of females. Among males, 10 cases were of Early and 11 were of Moderately advanced stage and among females four cases were of Early and 5 were of Moderately advanced stage. $66.66 \%$ of the cases had habit of consuming areca nut and rest had habit of consuming areca nut and betel quid (Table 1). All cases had history of areca nut chewing of at least 7 years.

Cases with juxtaepithelial area showing hyalinization, plump young fibroblasts in moderate numbers, dilated and congested blood vessels and inflammatory cells mostly mononuclear lymphocytes, eosinophils and occasional plasma cell were considered as Early Stage (Fig 1A) whereas cases with moderately hyalinized collagen, comprising mostly fibrocytes, normal or constricted blood vessels, inflammatory cells mostly lymphocytes and plasma cells with occasional eosinophils were considered as Moderately
Table 1. Characteristic of study groups.

\begin{tabular}{llll} 
& Early Stage & $\begin{array}{l}\text { Moderately Ad- } \\
\text { vanced Stage }\end{array}$ & Normal \\
\hline Numbers & 14 & 16 & 20 \\
\hline $\begin{array}{l}\text { Age (mean) } \\
\text { (years) }\end{array}$ & 47.5 & 42.2 & 41.2 \\
\hline Gender & Male: 10 & Male: 11 & Male: 13 \\
\hline Habits & Female: 4 & Female: 5 & Female: 7 \\
Areca Nut & Male -5 & Male -8 & Absent \\
\hline & Female -4 & Female -3 & \\
\hline
\end{tabular}

$\begin{array}{lcc}\text { Areca Nut and Betel Quid } & \\ \text { Male }-5 & \text { Male }-3 & \text { Absent } \\ \text { Female }-0 & \text { Female }-2 & \end{array}$

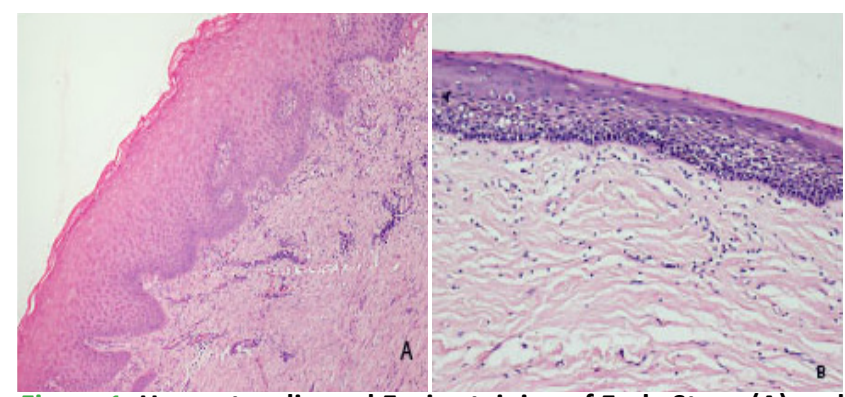

Figure 1. Haematoxylin and Eosin staining of Early Stage (A) and Moderately advanced stage (B). (10X)

Advanced OSF cases according to Sirsat and Pindborg. ${ }^{6}$ (Fig 1B)

\section{Expression of MMP-2 and TIMP-2 in Normal Oral Mucosa and cases of OSF}

The expressions of MMP-2 and TIMP-2 in the normal control specimen from normal buccal mucosa were not evident except for the endothelial cells. The expression of MMP-2 was also observed in the cytoplasm of columnar cells, secretory cells and inflammatory cells of the stroma of inflammatory bowel. (Fig 2A) The fibroblasts of fibro collagenous stroma and endothelial cells lining the blood vessel of placental tissue showed positive expression to TIMP-2 (Fig 2B). The endothelial cells were taken as internal positive control. As negative control, the sections of OSF were stained without primary antibody. Heterogeneous pattern of staining of MMP-2 and TIMP-2 were observed in both the stages of OSF. Out of 14 Early stage cases, $64.2 \%$ (nine cases) for MMP-2 (Fig 3A) and $78.5 \%$ (11 cases) for TIMP-2 positive (Fig 4A) expression was observed both in the epithelium and connective tissue. Out of 14 Early stage OSF specimens only three did not express TIMP-2 positivity. All 16 Moderately advanced stage OSF specimens expressed positive immunostaining to MMP-2 and TIMP-2, both in the epithelium and connective tissue. (Fig 3B and 4B)

\section{Statistical Analysis}

Difference in expression of MMP-2 and TIMP-2 between normal buccal mucosa and Early and Moderately advanced stage OSF specimens was found to be statistically significant 

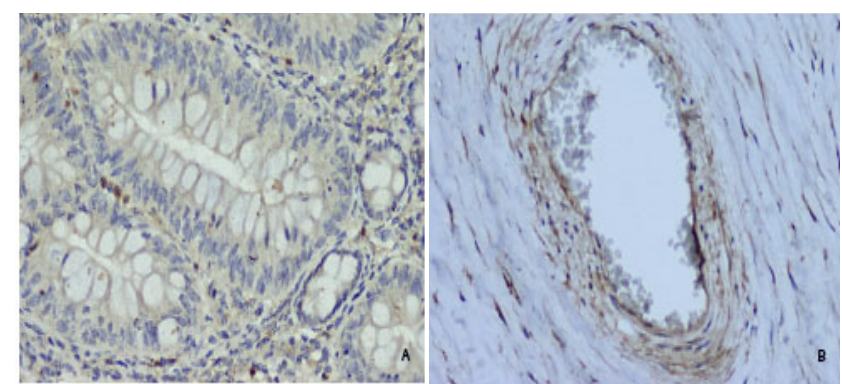

Figure 2. Immunohistochemical staining of Inflammatory Bowel (A) and Placenta (B) as positive controls for MMP-2 and TIMP-2, respectively. (20X)

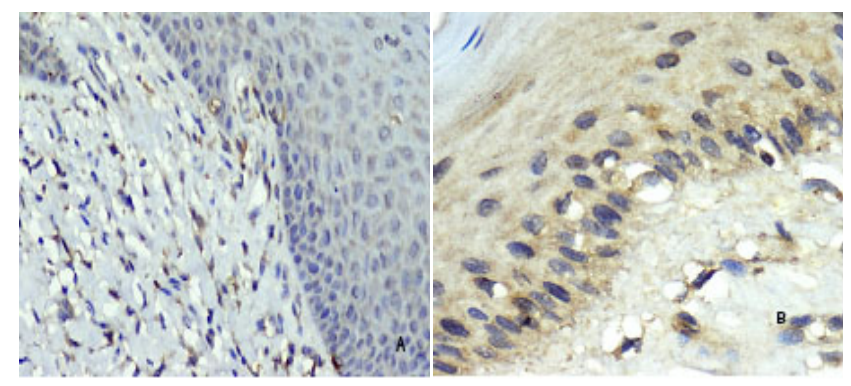

Figure 3. Diffuse staining of MMP-2 appreciated in Early (A) and Moderately advanced (B) stage cases of OSF. (40X)
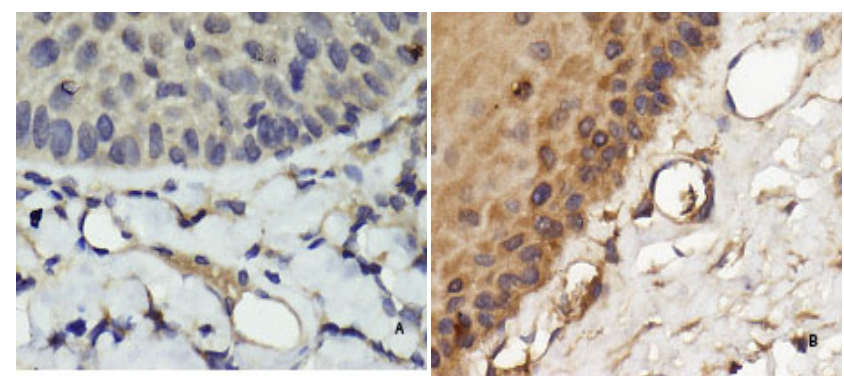

Figure 4. Intense staining of TIMP-2 in Early (A) and Moderately advanced (B) stage cases of OSF. (40X)

$(p<0.001)$ (Table 2 and 3). Altered expression of MMP-2 and TIMP-2 from normal to abnormal pathological tissue can suggest there distinctive role.

There was a significant difference in the expression of MMP-2 between basal and supra basal layer of the epithelium $(p<0.008)$ of both the stages of OSF. Also a significant difference $(p<0.008)$ in expression of MMP-2 was observed between the lamina propria and supra basal layer in Moderately advanced stage cases, highlighting the active modulation taking place in the juxtaepithelial region of connective tissue and basal layer of epithelium and activeness in Epithelium Mesenchymal Interaction (Table 4). A statistical significant difference was noted only in the lamina propria region when both stages were compared for MMP-2 staining $(p<0.05)$ (Table 5). Similar comparison between the stages of OSF expressed a significant difference for TIMP-2 in supra basal, lamina propria and deep connective tissue areas $(p<0.05)$ (Table 6$)$.
Table 2. Comparison Among Cells Expressing MMP-2 Between Normal and Different Stages of OSF (Kruskal Wallis Test).

\begin{tabular}{|c|c|c|c|c|c|c|c|}
\hline Groups & Stage & $\begin{array}{l}\text { Num- } \\
\text { ber }\end{array}$ & Zones & Mean & $\begin{array}{l}\text { Stan- } \\
\text { dard } \\
\text { Devia- } \\
\text { tion }\end{array}$ & $\begin{array}{l}\text { Me- } \\
\text { dian }\end{array}$ & $\begin{array}{l}p \\
\text { value }\end{array}$ \\
\hline \multirow{4}{*}{$\begin{array}{l}\text { Nor- } \\
\text { mal }\end{array}$} & & 10 & BA & 0.00 & 0.00 & 0.00 & \multirow{12}{*}{$\begin{array}{l}p<0 . \\
001\end{array}$} \\
\hline & & & SB & 0.00 & 0.00 & 0.00 & \\
\hline & & & LP & 0.00 & 0.00 & 0.00 & \\
\hline & & & Deep CT & 0.00 & 0.00 & 0.00 & \\
\hline \multirow[t]{8}{*}{ OSF } & Early & 14 & BA & 21.6 & 24.0 & 13.1 & \\
\hline & & & SB & 9.9 & 11.7 & 4.8 & \\
\hline & & & LP & 20.9 & 20.5 & 23.2 & \\
\hline & & & Deep CT & 17.1 & 17.0 & 17.7 & \\
\hline & \multirow{4}{*}{$\begin{array}{l}\text { Mod- } \\
\text { erately } \\
\text { Ad- } \\
\text { vanced }\end{array}$} & 16 & BA & 35.4 & 29.9 & 28.0 & \\
\hline & & & SB & 18.8 & 18.8 & 14.6 & \\
\hline & & & LP & 37.0 & 23.92 & 37.4 & \\
\hline & & & Deep CT & 32.4 & 22.98 & 30.1 & \\
\hline
\end{tabular}

BA = Basal, SB = Supra basal, LP = Lamina propria, Deep CT = Deep connective tissue

Table 3. Comparison Among Cells Expressing TIMP-2 Between Normal and Different Stages of OSF (Kruskal Wallis Test).

\begin{tabular}{|c|c|c|c|c|c|c|c|}
\hline Groups & Stage & $\begin{array}{l}\text { Num- } \\
\text { ber }\end{array}$ & Zones & Mean & $\begin{array}{l}\text { Stan- } \\
\text { dard } \\
\text { Devia- } \\
\text { tion }\end{array}$ & $\begin{array}{l}\text { Me- } \\
\text { dian }\end{array}$ & $p$ value \\
\hline \multirow[t]{4}{*}{ Normal } & & 10 & BA & 0.00 & 0.00 & 0.00 & \\
\hline & & & SB & 0.00 & 0.00 & 0.00 & \\
\hline & & & LP & 0.00 & 0.00 & 0.00 & \\
\hline & & & $\begin{array}{l}\text { Deep } \\
\text { CT }\end{array}$ & 0.00 & 0.00 & 0.00 & \\
\hline \multirow[t]{8}{*}{ OSF } & Early & 14 & BA & 18.9 & 16.6 & 17.1 & \\
\hline & & & SB & 7.3 & 10.0 & 2.7 & \\
\hline & & & LP & $\begin{array}{l}23 . \\
1\end{array}$ & 16.2 & 22.6 & $\begin{array}{l}p<0 \\
001\end{array}$ \\
\hline & & & $\begin{array}{l}\text { Deep } \\
\text { CT }\end{array}$ & 20.1 & 18.34 & 17.5 & \\
\hline & \multirow{4}{*}{$\begin{array}{l}\text { Mod- } \\
\text { erately } \\
\text { Ad- } \\
\text { vanced }\end{array}$} & 16 & BA & 32.4 & 25.5 & 21.4 & \\
\hline & & & SB & 19.4 & 19.8 & 13.2 & \\
\hline & & & $\mathrm{LP}$ & 39.7 & 18.0 & 35.4 & \\
\hline & & & $\begin{array}{l}\text { Deep } \\
\text { CT }\end{array}$ & 35.4 & 19.8 & 33.7 & \\
\hline
\end{tabular}

BA = Basal, SB = Supra basal, LP = Lamina propria, Deep CT = Deep connective tissue 
Table 4. Data Showing the Multiple Comparisons Between Different Zones of Early and Moderately Advanced Stage Cases for MMP-2 and TIMP-2 Positive Cells.

\begin{tabular}{|c|c|c|c|c|c|}
\hline Stage & $\begin{array}{l}\text { Between } \\
\text { Zones }\end{array}$ & $\begin{array}{l}\text { MMP-2 } \\
\text { Test sta- } \\
\text { tistic }\end{array}$ & $p$ value & $\begin{array}{l}\text { TIMP-2 } \\
\text { Test statistic }\end{array}$ & $\begin{array}{l}p \\
\text { value }\end{array}$ \\
\hline \multirow[t]{6}{*}{ Early } & $B A-S B$ & 2.67 & .003 & 2.93 & .003 \\
\hline & LP - BA & .30 & .767 & 1.60 & .110 \\
\hline & $\begin{array}{l}\text { Deep CT- } \\
\text { BA }\end{array}$ & .77 & .441 & .00 & 1.00 \\
\hline & $L P-S B$ & 2.07 & .038 & 2.93 & .003 \\
\hline & $\begin{array}{l}\text { Deep CT } \\
\text { - SB }\end{array}$ & 1.48 & .139 & 2.49 & .013 \\
\hline & $\begin{array}{l}\text { Deep } \\
\text { CT- LP }\end{array}$ & 1.36 & 1.73 & .89 & .374 \\
\hline \multirow{6}{*}{$\begin{array}{l}\text { Mod- } \\
\text { erately } \\
\text { Ad- } \\
\text { vanced }\end{array}$} & $B A-S B$ & 2.67 & .008 & 2.64 & .008 \\
\hline & $L P-B A$ & .97 & .334 & 1.91 & .056 \\
\hline & $\begin{array}{l}\text { Deep CT- } \\
\text { BA }\end{array}$ & .17 & .865 & .72 & .469 \\
\hline & $\mathrm{LP}-\mathrm{SB}$ & 2.84 & .005 & 2.74 & .006 \\
\hline & $\begin{array}{l}\text { Deep CT- } \\
\text { SB }\end{array}$ & 1.99 & .047 & 2.59 & .010 \\
\hline & $\begin{array}{l}\text { Deep } \\
\text { CT- LP }\end{array}$ & 1.59 & .112 & 1.14 & .255 \\
\hline
\end{tabular}

BA = Basal, SB = Supra basal, LP = Lamina Propria, Deep CT = Deep connective tissue, $p<0.008=$ Significant; Value is based on Wilcoxon Signed Ranks Test

Table 5. Comparison Between Early and Moderately Advanced Stage Cases for MMP-2 Positive Cells.

\begin{tabular}{lcc} 
Zones & Mann-Whitney U Test & p value \\
\hline Basal & 1.51 & 0.13 \\
Suprabasal & 1.46 & 0.14 \\
Lamina propria & 1.98 & 0.04 \\
$\begin{array}{l}\text { Deep connective } \\
\text { tissue }\end{array}$ & 1.90 & 0.05
\end{tabular}

$p<0.05=$ Significant; Value based on Mann Whitney U Test

Table 6. Comparison Between Early and Moderately Advanced Stage Cases for TIMP-2 Positive Cells.

\begin{tabular}{|lcc|}
\hline Zones & Mann-Whitney U Test & p value \\
\hline Basal & 1.37 & 0.17 \\
\hline Suprabasal & 2.07 & 0.03 \\
\hline Lamina propria & 2.45 & 0.01 \\
$\begin{array}{l}\text { Deep connective } \\
\text { tissue }\end{array}$ & 2.10 & 0.03 \\
\hline
\end{tabular}

$p<0.05$ = Significant; Value based on Mann Whitney U Test

\section{DISCUSSION}

OSF, a premalignant condition of the oral cavity, is a disease where there is pathological fibrosis affecting the oral mucosa and contiguous areas of the upper aero digestive tract. ${ }^{6}$ It has a relentless course of progression and is not amenable to reversal at any stage of the disease process. ${ }^{7}$ The exact cause for the stromal changes with consequent deposition of fibrous tissue in the submucosa still remains enigmatic. Though many theories have been proposed in elucidating the pathological pathway, role of areca nut and its products in the pathogenesis of OSF has been established. ${ }^{2}$ There is an imbalance between accumulation of collagen and other proteins in the stroma with a decreased turnover of the same.

Maintenance of connective tissue homeostasis is a crucial event for normal functioning of the tissue. Various cytokines, growth factors and enzymes are said to play a pivotal role in regulating the remodeling of ECM. Among these are MMPs and their inhibitors. In normal physiological processes like embryonic development, morphogenesis, reproduction, etc; MMPs and TIMPs form a complex biological system strictly controlling the degradation of ECM and can be produced by many different cell types like skin fibroblasts, keratinocytes, chondrocytes, endothelial cells, monocytes, osteoblasts and has been found in body fluids such as saliva, gingival crevicular fluid (GCF), serum and urine..$^{8-10}$

The dynamic balance between MMPs and TIMPs is one of the decisive factors for the maintenance of ECM homeostasis and integrity. Disruption of this balance may result in disease associated with uncontrolled turnover of matrix. A diverse expression of these proteases has been reported in various lesions such as arthritis, human portal pipe-stem fibrosis, fibrotic human liver, periodontal diseases, various premalignant lesions and cancer, wherein they are found to play an important role in modulating ECM for the progression of disease. Thus evaluation of these enzymes might also provide an insight into the disease process in OSF. ${ }^{10-16}$

In the present study cells positive for both MMP-2 and TIMP-2 were found to increase significantly from early to moderately advanced stages when compared to the normal buccal mucosa. These findings where in accordance with studies of Rajendran et al and Maatta et al wherein they found an increase in the activity of these proteases and their inhibitors in OSF and vulvar intraepithelial neoplasia (a premalignant condition), respectively. ${ }^{16,17}$ Elevated levels of these enzymes have been implicated in the course of several physiological and pathological conditions when rearrangement of the original tissue architecture occurs. ${ }^{18}$

The expressions of TIMP-2 positive cells were more in moderately advanced when compared to early stage with a statistical significance $(p<0.05)$ in majority of the zones i.e., lamina propria, deep connective tissue and supra basal layers, which could be related to its over production that could prevent matrix degradation. This accounts to the 
clinical fibrosis which is extensive in advanced cases when compared to early OSF. Increase in the expression of MMP2 was noted only in lamina propria $(p<0.05)$ between both the stages, as in accordance to the study by Rajendran et al, however was in contrast to the studies by Chang et al. ${ }^{10,17}$

It has also been found that areca nut extract can stimulate collagen synthesis and might also stabilize the collagen fibers. This has found to have increase resistance of collagen to degradation by mammalian fibroblast proteases. ${ }^{19}$ Also an increase in MMP-2 secretion is thought to be brought about by a pro-fibrotic cytokine, TGF- $\beta$. This cytokine is induced by areca nut and its products and hence is critical for the pathogenesis of OSF. ${ }^{20}$ Further; MMP-2 was shown to influence cell-surface receptor-mediated signaling by releasing the active ectodomain of fibroblast growth receptor-1, which in turn could influence fibrosis. ${ }^{21}$

As the re-modulation of tissue reaches a stage of fibrosis, which is considered to be irreversible the appropriate source or activity of MMPs is no longer present. ${ }^{22}$ With further increase in TIMPs in these conditions, the process of fibrosis is enhanced and is impossible to revert. Thus these events could be related to OSF wherein a chronic inflammatory process is evident.

Although there was a significant expression of MMP-2 and TIMP-2 noted in various zones of the antibodies, no significant difference in the expression of MMP-2 and TIMP2 was found when compared within the same stage of OSF. These findings were in concurrent with findings of Benyon et al where they concluded that, in advanced disease though there was an increase in the expression of MMP2 , its activity in the later stages may be inhibited by the concomitant up regulation of TIMP-1 and TIMP-2, where in TIMP-2 is known to bind specifically to the C- terminal portion of the pro gelatinase A (proMMP-2) and prevents its conversion to the active form. ${ }^{13,23}$ Alternatively up regulation of MMPs with a proportional increase in TIMPs can be explained by the fact that they can be regulated independently or sometimes reciprocally. ${ }^{24}$

It has been observed that following inflammation there is an increase in the amount of MMPs. Studies by Lu et al have identified the induction of MMP-2 activation in oral fibroblasts by areca nut extract treatment compared to normal fibroblast in which they confirmed that induced fibroblast had increased MMP-2 mRNA expression and three-fold increase in MMP-2 secretion. ${ }^{25}$ This could provide a favorable environment for the activation of growth factors that may contribute significantly to the progression of OSF to oral carcinomas. Study by Gaiotto et al in their study of cervical intraepithelial neoplasia found that an increase in the levels of MMP-2 in the advancing grade could be a warning signal of carcinogenesis. ${ }^{15}$ In our study we observed that with the histopathological severity of OSF the expression of MMP-2 was found to increase which substantiates its role in disease progression and tendency for carcinogenesis.
The expression of MMP-2 and TIMP-2 by the keratinocytes in OSF might suggest its role in modulation of ECM in the disease progression. In our study with advancing stage, we found a statistical significant increase number of cells expressing MMP-2 and TIMP-2 in the basal compared supra basal layers and also in lamina propria when compared to the deep connective tissue, however it was not statistical significant. This could be related that the disease activity may be more pronounced at basal and lamina propria region, as the changes are evident in these region of the epithelium and connective tissue.

Keratinocyte derived mediators are the initiators for mucosal inflammation. The areca nut extracts induce uncontrolled DNA synthesis and morphological alteration in keratinocytes. ${ }^{26}$ The study on affect of areca nut in gingival keratinocytes by Jeng et al have found that keratinocytes secrete a variety of profibrotic cytokines like TGF- $\beta$ participating in a bi-directional communication network with neighboring fibroblasts whereby each cell type influences the proliferation/survival of the other which produces certain chemokines which induce Interleukin-6 (IL-6), prostaglandin E2 (PGE2) and TNF- $\alpha$ that could diffuse through the basement membrane and initiate changes in the connective tissue. ${ }^{26}$ This could account for the characteristic sub-epithelial hyalinization in the lamina propria region and the changes in the basal keratinocyte seen under routine staining. Further it can be reasoned that betel nut and its products can play an important role in activation of these proteases.

Few cases of early and advanced OSF cases did not exhibit staining for MMP-2 and TIMP-2. Here other proteases and its inhibitors along with cytokines and growth factors could have played an important role. In the present study expression of MMP-2 and TIMP-2 was not evident in keratinocytes and fibroblasts in the normal buccal mucosa which was in accordance to the other studies by Sutinen et al, Hong $Q$ et al and Samantaray et al. ${ }^{18,27,28}$ Only the endothelial cells were found to be positive to MMP-2 and TIMP-2, which is needed to maintain tissue homeostasis.

In our study, though we found an increase in MMP-2 and TIMP-2 expression in various stages of OSF, one cannot state with any certainty whether an intense signal is due to an increased production and storing of these proteases or raised activation and secretion. Hence combination of various molecular markers along with advanced techniques would aid in detecting the enzyme activity necessary to be employed for further studies.

\section{CONCLUSION}

In the present study, we attempted to compare and correlate the expression of MMP-2 and TIMP-2 in keratinocytes and fibroblasts in specimens of OSF. The expression of MMP-2 and TIMP-2 though not significant in all the areas were found to increase with advancing stages. 
Increase in fibrosis despite the increased expression of MMP-2 explains the inhibitory action of concomitant increase in TIMP-2 expression which renders the MMP-2 in its inactive form. Also the increase in TIMP-2 correlates with the increasing fibrosis with advancing stages of OSF. The present study analyzed the expression of MMP-2 and TIMP2 on keratinocytes which is said to be one of the factors responsible in the Epithelial Mesenchymal Transition in the pathogenesis of OSF. However, the conclusions in this research are with minimal samples and limited to the semi quantitative analysis, more definitive methods are required to establish the roles of metabolites of areca and other proteases to define the exact nature of the fibrosis and its potentiality to malignant transformation.

\section{REFERENCES}

1. Warnakulasuriya S, Johnson NW, van der Waal I. Nomenclature and classification of potentially malignant disorders of the oral mucosa. $J$ Oral Pathol Med. 2007; 36: 575-80.

2. Trivedy CR, Craig G, Warnakulasuriya S. The oral health consequences of chewing areca nut. Addict Biol. 2002; 7: 115-25.

3. International Agency for Research on Cancer. Betel-quid and areca nut chewing and some areca nut derived nitrosoamines. Lyon: IARC. 2004(85):123-9.

4. Woessner JF Jr. Matrix metalloproteinases and their inhibitors in connective tissue remodeling. FASEB J. 1991; 5: 2145-54.

5. Stetler-Stevenson WG, Liotta LA, Kleiner DE Jr. Extracellular matrix 6: role of matrix metalloproteinases in tumor invasion and metastasis. FASEB J. 1993; 7: 1434-41.

6. Pindborg JJ, Sirasat SM. Oral Submucous fibrosis. Oral Surg Oral Med Oral Pathol. 1966; 22: 764-69.

7. Rajendran R, Sunil, Twinkle SP, Anikumar TV, Annie J. Cell death does not herald epithelial involution ("atrophy") in oral sub mucous fibrosis: a TEM study. Indian J Dent Res. 2004; 15: 13-19.

8. Birkedal-Hansen H, Moore WGI, Bodden MK, WindsorLJ, DeCarlo A, Engler JA. Matrix Metalloproteinases: A Review. Critical Reviews in Oral Biology and Medicine. 1993;4(2):197-250.

9. Verstappen J and Von den Hoff JW. Tissue Inhibitors of Metalloproteinases (TIMPs): Their Biological Functions and Involvement in Oral Disease. J Dent Res. 2006; 85(12):1074-1084.

10. Chang YC, Yang SF, Tai KW, Chou MY, Hsieh YS. Increased tissue inhibitor of metalloproteinase-1 expression and inhibition of gelatinase A activity in buccal mucosal fibroblasts by arecoline as possible mechanisms for oral submucous fibrosis. Oral Oncology. 2002;38:195-200.

11. Brew K, Dinakarpandian D, Nagase H. Tissue inhibitors of metalloproteinases: evolution, structure and function. Biochim Biophys Acta. 2000; 1477: 267-83.

12. Gomez DE, De Lorenzo MS, Alonso DF, Andrade ZA. Expression of metalloproteinases (MMP-1, MMP-2 and MMP-9) and their inhibitors (TIMP-1 and TIMP-2) in schistosomal portal fibrosis. Am J Trop Med Hyg. 1999; 61: 9-13.

13. Benyon RC, Iredale JP, Goddard S, Winwood PJ, Arthur MJ. Expression of tissue inhibitor of metalloproteinases 1 and 2 is increased in fibrotic humanliver. Gastroenterology. 1996; 110: 821-31.

14. Soell M, Elkaim R, Tenenbaum H. Cathepsin C, matrix metalloproteinases, and their tissue inhibitors in gingiva and gingival crevicular fluid from periodontitis-affected patients. J Dent Res. 2002; 81: $174-78$.
The results obtained from our study might provide a basis for considering MMP-2 and TIMP-2 as important profibrotic mediators in the pathogenesis and progression of oral submucous fibrosis, which could aid in identifying the aggressiveness of the lesion and elucidate its role in malignant transformation. Finally, it would be extremely interesting to study the finest regulation of MMP-2 and TIMP-2 activity as a possible target for fibrosis treatment.

\section{ACKNOWLEDGEMENT}

We would like to thank Mrs. Sangeetha Perdoor for the technical assistance.

15. Gaiotto MA, Focchi J, Ribalta JL, Stavale JN, Baracat EC, Lima GR, et al. Comparative study of MMP-2 (Matrix Metalloproteinase-2) immune expression in normal uterine cervix, intraepithelial neoplasias, and squamous cells cervical carcinoma. Am J Obstet Gynecol. 2004; 190: 1278-82.

16. Määttä $M$, Santala $M$, Soini $Y$, Turpeenniemi-Hujanen $T$, TalvensaariMattila A. Increased matrix metalloproteinases 2 and 9 and tissue inhibitor of matrix metalloproteinase 2 expression is associated with progression from vulvar intraepithelial neoplasia to invasive carcinoma. Acta Obstet Gynecol Scand. 2010; 89: 380-84.

17. Rajendran R, Rajeesh Mohammed PK, Shaikh SS, Pillai MR. Expression of matrix metalloproteinases (MMP-1, MMP-2 and MMP-9) and their inhibitors (TIMP-1 and TIMP-2) in oral submucous fibrosis. Ind J Dent Res. 2006:17(4):161-166.

18. Sutinen M, Kainulainen T, Hurskainen T, Pillai MR. Expression of matrix metalloproteinases (MMP-1 and -2) and their inhibitors (TIMP-1, -2 and -3 ) in oral lichen planus, dysplasia, squamous cell carcinoma and lymph node metastasis. Br J Cancer.1998; 77: 2239-45.

19. Scutt A, Meghji S, Canniff JP, Collins HM, Steele RJ. Stabilisation of collagen by betel nut polyphenols as a mechanism in oral submucous fibrosis. Experientia. 1987; 43: 391-93.

20. Overall CM, Wrana JL, Sodek J. Independent regulation of collagenase, 72-kDa progelatinase, and metallo endoproteinase inhibitor expression in human fibroblasts by transforming growth factor-beta. J Biol Chem. 1989; 264: 1860-69.

21. Levi E, Fridman R, Miao HQ, Ma YS, Yayon A, Vlodavsky I. Matrix metalloproteinase 2 releases active soluble ectodomain of fibroblast growth factor receptor 1. Proc Natl Acad Sci USA. 1996; 93: 7069-74.

22. Issa $\mathrm{R}$, Zhou X, Constandinou CM, Fallowfield J, Millward-Sadler $H$, Gaca MD. Spontaneous recovery from micronodular cirrhosis: evidence for incomplete resolution associated with matrix crosslinking. Gastroenterology. 2004; 126: 1795-1808.

23. Xia L, Tian-You L, Yi-Jun G, Dong-sheng T, Wen-Hui L. Arecoline and oral keratinocytes may affect the collagen metabolism of fibroblasts. J Oral Pathol Med. 2009;38: 422-426.

24. Parsons SL, Watson SA, Brown PD, Vesterlund E, Alexander JP, Overall CM, et al. Matrix metalloproteinases. Br J Surg. 1997; 84: 160-66.

25. Lu HH, Liu CJ, Liu TY, Kao SY, Lin SC and Chang KW. Areca-treated Fibroblasts enhance tumorigenesis of oral epithelial cells. J Dent Res 2008;87(11):1069-74.

26. Jeng JH, Hahn LJ, Lin BR, et al. Effects of areca nut, inflorescence piper betel extracts and arecoline on cytotoxicity, total and unscheduled DNA synthesis in cultured gingival keratinocytes. J Oral Pathol Med.1999;28:64-71. 
27. Hong $Q$, Jun $T$, Jin L, Xiling J, Tamamura R. Expression and clinical significance of matrix metalloproteinase-2 and inhibitor TIMP-2 in oral squamous cell carcinoma. J Hard Tissue Biology. 2006;15: 54-60.
28. Samantaray S, Sharma R, Chattopadhyaya TK, Gupta SD, Ralhan R. Increased expression of MMP-2 and MMP-9 in esophageal squamous cell carcinoma. J Cancer Res Clin Oncol. 2004; 130: 37-44. 